\title{
Turismo Rural versus o Turismo Não-Rural: estudos de casos em Roraima
}

\section{Rural Tourism versus Non-Rural Tourism: case studies in Roraima (Brazil)}

\author{
Suelen Santos Bezerra, Georgia Patrícia da Silva Ferko
}

RESUMO: As características do destino turístico, a divulgação, os comentários e o conhecimento sobre os locais que praticam o turismo rural, possuem grande influência sobre o despertar do interesse dos turistas em conhecer essas propriedades que desenvolvem o turismo rural. Além de trazer benefícios para as que fazem do turismo rural fonte de renda ou de complementação da renda familiar. O objetivo principal é avaliar as possíveis causas que impedem o desenvolvimento turismo rural no Estado de Roraima, com base na experiência de empresas integrantes no projeto "Vivendo Roraima pelos Cavalos Lavradeiros", projeto este que foi criado para fortalecer o turismo rural no Estado. Em relação aos objetivos é descritiva. Para a coleta de dados, realizou-se pesquisa bibliográfica e pesquisa documental. Foram realizadas entrevistas junto aos proprietários das propriedades que dispuseram a colaborar com a pesquisa. Constatou-se que das dez propriedades que compõem este projeto, o qual foi resultado de uma parceria entre o Departamento de Turismo da SEPLAN (Secretaria Estadual de Planejamento e Desenvolvimento) do Estado de Roraima, e o SEBRAE-RR, seis delas não praticam o turismo rural. Dentre os motivos percebeu-se que estão relacionados à: falta de divulgação, ausência de turistas e visitantes no local, falta de incentivo aos proprietários, ausência de incentivos e apoio governamental e principalmente a não caracterização de turismo rural em algumas propriedades que possuem como atividade o camping, balneários, e outra que só permite ao visitante conhecer plantações de açaí para comercialização. Além disso, algumas propriedades que não se encontram abertas ao público por alguns outros motivos, os quais não foram devidamente esclarecidos. Conclui-se que não existe um projeto de turismo rural consolidado para Roraima, o que reflete pouco interesse dos órgãos governamentais e iniciativa privada. Tal fato inibe a possibilidade de ter mais uma alternativa emergente da valorização do território, podendo-se se constituir um importante instrumento de desenvolvimento para as regiões. Espera-se que este estudo sirva de ferramenta para identificar elementos, como os pontos a serem aperfeiçoados, com o intuito desenvolver estratégias de maneira a potencializar todas estas forças que o turismo rural pode proporcionar, em Roraima.

PALAVRAS-CHAVE: Turismo Rural; Propriedades; Destino; Desenvolvimento. 


\section{ABSTRACT}

The characteristics of the tourist destination, disclosure, comments and knowledge of local practicing rural tourism, have great influence on the awakening of the interest of tourists to know those properties that develop rural tourism. In addition to bringing benefits to making rural tourism source of income or to supplement the family income. The main objective is to evaluate the possible causes that prevent rural tourism development in the state of Roraima, based on the experience of companies participating in the project "Vivendo Roraima pelos Cavalos Lavradeiros" project that has been created to strengthen rural tourism in the state. In relation to the objectives it is descriptive. For data collection, there was literature and documentary research. Interviews were conducted with owners of properties that volunteered to participate in the study. It was found that of the ten properties that make up this project, which was the result of a partnership between the Department of Tourism SEPLAN (State Department of Planning and Development) of the State of Roraima, and SEBRAE -RR, six of them do not practice rural tourism. Among the reasons it was realized that are related to: lack of disclosure, lack of tourists and visitors on site, lack of incentives to owners, lack of incentives and government support and especially not the characterization of rural tourism in some properties that have as activity camping, showers, and one that only allows the visitor to know açai plantations marketing. Additionally, some properties that are not open to the public by some other reasons, which have not been properly clarified. We conclude that there is no consolidated rural tourism project to Roraima, which reflects little interest from government agencies and private enterprise. This fact inhibits the possibility of having more an emerging alternative development of the area, being able to be an important development for the regions. It is expected that this study will serve as a tool for identifying elements, such as the points to be improved in order to develop strategies to maximize way all these forces that rural tourism can provide in Roraima.

KEYWORDS: Rural Tourism; Properties; Destiny; Development.

\section{Introdução}

No contexto do mundo atual, o turismo tornou-se um dos setores mais competitivos na captação de financiamentos internos e externos, especialmente no que diz respeito à economia nacional e internacional, sendo expressivo no PIB (Produto Interno Bruto) Mundial. Segundo a OMT (Organização Mundial do Turismo), haverá um crescimento no setor entre 4\% a $5 \%$ ao ano, o qual poderá atingir cifras de $6,7 \%$ no ano de 2020 , enquanto se estima para a economia mundial um crescimento inferior a $3 \%$ no mesmo período (BARTELÓ, 2000).

As primeiras investidas teóricas sobre o tema foram dos economistas, em função da sua importância econômica em termos globais, regionais e locais. Isso fez com que a atividade turística passasse a ser considerada como um agente do entendimento internacional, que tem como alternativa promover a superação da condição de pobreza e dependência dos países subdesenvolvidos diante das economias centrais (BANDUCCI JR., 2001).

Em razão dessa movimentação de recursos, o turismo tem sido alvo de pesquisas e de grande interesse na agenda política; e em função de sua 
importância econômica, tem sido incentivado por governos que muitas vezes colocam em segundo plano outras funções de igual importância e os desdobramentos dessa prática

Embora a atividade turística seja uma alternativa que pode ser desenvolvida em vários locais, é preciso que ela seja praticada de forma sustentável, e com a responsabilização de todos os atores envolvidos, para que não haja a degradação do meio ambiente e venha a ser pivô de problemas na comunidade receptora. Essa preocupação passa a ser real, na medida em que houver uma tendência do aumento da demanda por áreas naturais. O turismo, ecológico, naturalista, personalizado e realizado em grupos pequenos tende a caracterizar os fluxos turísticos do futuro (RUSCHMANN, 1999).

Devido à ausência de preocupação nos impactos do turismo pelos planejadores e empreendedores do setor, há registros de efeitos negativos em localidades que promovem o turismo (DANTAS; MELO, 2008; BETTI; DENARDIN, 2013). Hoje, são encontrados na literatura vários mecanismos de gestão e conservação, cujo objetivo é minimizar os impactos negativos e ressaltar os aspectos positivos que a atividade turística pode causar às comunidades locais e ao meio ambiente, tais como indicadores de sustentabilidade, que proporcionam a análise dos níveis sustentáveis de um determinado local objeto de estudo pelas dimensões sociais, ambientais, econômicas, institucionais (SOUZA; ANDRADE; CÂNDIDO, 2010), culturais, turísticas (SANTOS, 2013), política-Institucional e territorial (FALCÃO; GÓMEZ, 2012).

O turismo rural deve se desenvolver de forma que os critérios socioambientais que deverão conduzir à sustentabilidade sejam respeitados. Porém, o que vem se observando na prática em algumas localidades é a exploração dos ambientes naturais, numa distorção da realidade social local, que nem sempre usufrui dos benefícios do turismo. Logo, deve-se levar em consideração o aproveitamento do que o meio ambiente oferece e suas vantagens. A partir disso, devem ser utilizadas práticas semelhantes às do ecoturismo, dentre outros tipos de turismo que são oferecidos no meio rural (ALMEIDA, 2012).

O objetivo deste trabalho é avaliar as possíveis causas que impedem o desenvolvimento turismo rural no Estado de Roraima, com base na experiência de empresas integrantes no projeto "Vivendo Roraima pelos Cavalos Lavradeiros", projeto este que foi criado para fortalecer o turismo rural no Estado.

Ao se propor a atividade turística como produto capaz de gerar renda e inclusão da comunidade, faz-se necessário um conhecimento detalhado da realidade na qual se pretende agir. Assim, serão realizadas pesquisas para levantamento de dados sobre as especificidades das propriedades inclusas nesse roteiro de turismo rural. 


\title{
Referencial teórico
}

\section{Turismo Rural: delineando o espaço geográfico}

O turismo ao redor do mundo vem recebendo atenção pelo prisma econômico e sua alta potencialidade de movimentação de divisas. No Brasil, é possível identificar a atenção dos governantes e demais autoridades responsáveis quando criam políticas para fomentar essa prática, enaltecendo o efeito benéfico sobre a geração de emprego e renda.

Rodrigues (1997) aponta que o turismo transformou-se numa atividade econômica importante do mundo contemporâneo, recebendo cada vez mais atenção e também seriedade no seu tratamento científico e técnico.

Para Barbosa (2005, p. 108):

\begin{abstract}
O turismo é uma força econômica das mais importantes do mundo. Nele ocorrem fenômenos de consumo, originam-se rendas, criam-se mercados nos quais a oferta e a procura encontram-se. Os resultados do movimento financeiro decorrentes do turismo são por demais expressivos e justificam que esta atividade será incluída na programação da política econômica de todos os países, regiões e municípios.
\end{abstract}

Para Barbosa (2005, p. 107), "o turismo está relacionado com as viagens, porém não são todas as viagens que são consideradas como turismo. O conceito de turismo implica a existência de recursos naturais e/ou culturais e infraestrutura". Ele está, em grande parte, ligado ao meio ambiente, o oposto do que costuma acontecer nos outros setores, o que imviabiliza a realização de atividades de turismo sem levar isso em consideração (FONS; FIERRO; PATIÑO, 2011, v. 88, p. 553, tradução nossa).

$O$ fato é que, em função de suas modalidades, vem sendo caracterizado de diversas formas e recebendo algumas nomenclaturas, tais como: Ecoturismo, Turismo Cultural, Turismo Rural e Turismo de Aventura, entre outras.

Tendo definido o turismo, é importante ressaltar que há, porém, algumas diferenças entre o turismo e o espaço, mas na literatura é possivel encontrar definições básicas que permitem uma melhor compreensão das diferenças entre o espaço geográfico e o espaço turístico. O Quadro 1 mostra quais os itens correspondentes a cada tipo de espaço mencionado. É possível analisar os aspectos que caracterizam o espaço geográfico, pois ele diz respeito à população, empresas, instituições, infraestrutura e meio ecológico, pelos quais no espaço turístico é possível observar que são os itens que compõem cada espaço geográfico, cada um com sua respectiva característica. 
Quadro 1: Espaço geográfico e o espaço turístico.

Table 1: Geographical area and tourist space

\begin{tabular}{|c|c|}
\hline ESPAÇO GEOGRÁFICO & ESPAÇO TURÍSTICO \\
\hline \multirow{3}{*}{ População/Sociedade } & Demanda de turistas \\
\hline & Moradores locais \\
\hline & $\begin{array}{l}\text { Representantes de instituições públicas, privadas ligados ao } \\
\text { turismo }\end{array}$ \\
\hline \multirow{6}{*}{ Empresas } & Hospedagem \\
\hline & Restaurantes \\
\hline & Agências de turismo \\
\hline & Transportadoras turísticas \\
\hline & $\begin{array}{l}\text { Espaços para eventos } \\
\text { Serviços de lazer e entretenimento }\end{array}$ \\
\hline & Empresas de marketing e publicidade \\
\hline \multirow{5}{*}{ Instituições } & Superestrutura turística - instituições reguladoras da atividade \\
\hline & (OMT - Organização Mundial do Turismo, Ministério do \\
\hline & Turismo, Embratur - Instituto Brasileiro do Turismo, \\
\hline & Secretarias Estaduais e Municipais de Turismo, Entidades da \\
\hline & Classe Turística). \\
\hline \multirow{6}{*}{ Infraestrutura } & Serviços públicos \\
\hline & Transporte \\
\hline & Comunicação \\
\hline & Segurança \\
\hline & Educação \\
\hline & Saúde \\
\hline \multirow[t]{2}{*}{ Meio Ecológico } & Base física do trabalho humano \\
\hline & turismo sustentável \\
\hline
\end{tabular}

Fonte: adaptado de (ALBACH, 2010).

Source: Adapted from (ALBACH, 2010).

No caso do turismo rural, este vem ganhando uma proporção significativa para o público que busca descanso, atividades interioranas junto à natureza e a essência da vida no campo. Na Europa, é bem comum encontrar ofertas dessa modalidade; na França, é bastante representativo, já que muitas propriedades se dispõem a desenvolvê-lo; na Espanha, o setor público incutiu nas zonas rurais e povoados a possibilidade de construção de alojamentos em casas particulares; Já em Portugal, o turismo rural ocorre em propriedades de famílias, onde os turistas se hospedam apenas "em casas cadastradas e licenciadas de um órgão governamental" (ALMEIDA, 2012, p. $61)$.

No Brasil, a atividade do turismo pode ser considerada incipiente, embora a visitação a propriedades rurais seja uma prática conhecida em algumas regiões, passando a ganhar status de atividade econômica apenas na década de 1980 (BRASIL, 2008). Já em outros países, principalmente os europeus, o turismo é uma das principais fontes de renda. Destarte, aos 
poucos as pessoas começaram a se interessar por essa atividade, já que "a sociedade vem descobrindo a importância ambiental e o valor estratégico de manutenção da paisagem rural para a própria vida do planeta" (BRASIL, 2008, p. 13).

Embora sua expansão tenha ocorrido principalmente no Sudeste do país, pela diversidade e pela expansão do Brasil, o turismo rural, independente da época e da localidade, se desenvolveu absorvendo as características de cada região (ALMEIDA, 2012).

Acrescenta-se também o que diz respeito à busca por antigas práticas sociais e culturais. O turismo rural "fundamenta-se em aspectos que se referem ao turismo, ao território, à base econômica, aos recursos naturais e culturais e à sociedade" (BRASIL, 2010, p. 17).

A prática do turismo em áreas rurais não se limita apenas a buscar atividades no meio rural, lazer ou simplesmente para descanso.

\begin{abstract}
Apesar de os estudos turísticos há tempos se referirem à fuga da rotina pelos moradores urbanos, associada às novas práticas de lazer da sociedade contemporânea, a teoria da ruralidade situa os movimentos em outras proporções, ao indicar as possibilidades de influência do turismo nas transformações socioespaciais que reforçam a vida urbana e, ao mesmo tempo, revitalizam valores tradicionais, ressignificando antigas práticas sociais e culturais (ALMEIDA, 2009, p. 56).
\end{abstract}

Neste sentido, tudo que está inserido no meio ambiente, como as florestas, os rios, os animais, inclusive os patrimônios culturais locais, que aos poucos ganham maior valorização, pois o contato com a natureza proporciona ao visitante uma sensação única de tranquilidade que só é possível a partir do momento em que se chega ao ambiente rural.

Isso só é possível pela tradição que é mantida em comunidades rurais, que vivem com simplicidade e possuem uma imensa e diversificada forma de manutenção de vida e, principalmente, diferentes formas de lazer.

O sentido da ruralidade contempla relações do rural tradicional, que abrange lógicas e estruturas ligadas às práticas do campo tradicional, ao trabalho camponês e à rusticidade que despertam questões relativas à imagem atribuída pelos turistas que buscam as paisagens rurais e ao sentido do "novo" rural que é criado para atrair esses turistas (ALMEIDA, 2009).

De acordo com as orientações básicas do Ministério do Turismo (BRASIL, 2008), o turismo Rural pode ser compreendido a partir do detalhamento das ideias, as quais estão dispostas no Quadro 2. 
Quadro 2: Detalhamento do turismo rural e seus conceitos,

Table 2: Detail of rural tourism and its concepts.

\begin{tabular}{|c|c|}
\hline $\begin{array}{l}1 \text { Atividades } \\
\text { turísticas no meio } \\
\text { rural. }\end{array}$ & $\begin{array}{l}\text { As atividades de turismo rural constituem-se da oferta de serviços, } \\
\text { equipamentos e produtos de: Operação e agenciamento. Transporte. } \\
\text { Hospedagem. Alimentação. Recepção à visitação em propriedades } \\
\text { rurais. Recreação, entretenimento e atividades pedagógicas } \\
\text { vinculadas ao contexto rural. Eventos. }\end{array}$ \\
\hline 2 Meio rural & $\begin{array}{l}\text { A concepção de meio rural aqui adotada baseia-se na noção de } \\
\text { território, com ênfase no critério da destinação da terra e na } \\
\text { valorização da ruralidade. Assim, considera-se território um espaço } \\
\text { físico, geograficamente definido, geralmente contínuo, } \\
\text { compreendendo cidades e campos, caracterizados por critérios } \\
\text { multidimensionais, como ambiente, economia, sociedade, cultura, } \\
\text { política e instituições, e uma população com grupos sociais } \\
\text { relativamente distintos, que se relacionam interna e externamente por } \\
\text { meio de processos específicos, onde se pode distinguir um ou mais } \\
\text { elementos que indicam identidade e coesão social, cultural e } \\
\text { territorial. Nos territórios rurais, tais elementos manifestam-se, } \\
\text { predominantemente, pela destinação da terra, notadamente focada } \\
\text { nas } 20 \text { práticas agrícolas e na noção de ruralidade, ou seja, no valor } \\
\text { que a sociedade contemporânea concebe ao rural. Tal valor } \\
\text { contempla as características mais gerais do meio rural: a produção } \\
\text { territorializada de qualidade, a paisagem, a biodiversidade, a cultura e } \\
\text { certo modo de vida, identificados pela atividade agrícola, a lógica } \\
\text { familiar, a cultura comunitária, a identificação com os ciclos da } \\
\text { natureza. }\end{array}$ \\
\hline $\begin{array}{l}3 \\
\text { Comprometimento } \\
\text { com a produção } \\
\text { agropecuária }\end{array}$ & $\begin{array}{l}\text { É a existência da ruralidade, de um vínculo com as coisas da terra. } \\
\text { Dessa forma, mesmo que as práticas eminentemente agrícolas não } \\
\text { estejam presentes em escala comercial, o comprometimento com a } \\
\text { produção agropecuária pode ser representado pelas práticas sociais } \\
\text { e de trabalho, pelo ambiente, pelos costumes e tradições, pelos } \\
\text { aspectos arquitetônicos, pelo artesanato, pelo modo de vida, } \\
\text { considerados típicos de cada população rural. }\end{array}$ \\
\hline $\begin{array}{l}4 \text { Agregação de } \\
\text { valor a produtos e } \\
\text { serviços }\end{array}$ & $\begin{array}{l}\text { A prestação de serviços relacionados à hospitalidade em ambiente } \\
\text { rural faz com que as características rurais passem a ser entendidas } \\
\text { de outra forma que não apenas focadas na produção primária de } \\
\text { alimentos. Assim, práticas comuns à vida campesina, como manejo } \\
\text { de criações, manifestações culturais e a própria paisagem passam a } \\
\text { ser consideradas importantes componentes do produto turístico rural } \\
\text { e, consequentemente, valorizadas por isso. A agregação de valor } \\
\text { também se faz presente pela possibilidade de verticalização da } \\
\text { produção em pequena escala, ou seja, beneficiamento de produtos in } \\
\text { natura, transformando-os para que possam ser oferecidos ao turista, } \\
\text { sob a forma de conservas, embutidos, produtos lácteos, refeições e } \\
\text { outros. }\end{array}$ \\
\hline $\begin{array}{l}5 \text { Resgate e } \\
\text { promoção do } \\
\text { patrimônio } \\
\text { cultural e natural }\end{array}$ & $\begin{array}{l}\text { O Turismo Rural, além do comprometimento com as atividades } \\
\text { agropecuárias, caracteriza-se pela valorização do patrimônio cultural } \\
\text { e natural como elementos da oferta turística no meio rural. Assim, os } \\
\text { empreendedores, na definição de seus produtos de Turismo Rural, } \\
\text { devem contemplar com a maior autenticidade possível os fatores } \\
\text { culturais, por meio do resgate das manifestações e práticas regionais } \\
\text { (como o folclore, os trabalhos manuais, os costumes, as festas, os } \\
\text { "causos", a gastronomia etc.), e primar pela conservação do ambiente } \\
\text { natural, da paisagem e cultura (o artesanato, a música, a arquitetura } \\
\text { etc.) }\end{array}$ \\
\hline
\end{tabular}

Fonte: (BRASIL, 2008, p 19).

Source: (BRASIL, 2008, p 19). 
No Quadro 2, observa-se o detalhamento do turismo rural feito pelo Ministério do Turismo, que definiu cinco aspectos abordados com a respectiva caracterização sobre: atividades turísticas no meio rural; meio rural; comprometimento com a produção agropecuária; agregação de valor a produtos e serviços; e resgate e promoção do patrimônio cultural e natural, o que nos permite entender como o turismo rural está diretamente ligado ao meio ambiente e o resgate pelas atividades no ambiente natural.

Cury (2012) afirma que a paisagem do espaço está relacionada com o tipo de solo, relevo, clima, fauna e flora do lugar. Quanto às paisagens rurais, estas se classificam como: paisagens naturais (onde não há ação humana), paisagens com ação antrópica limitada paisagens com presença de agricultura tradicional (podendo ser agricultura para subsistência ou para fins comerciais) e paisagem de uso agrário intensivo.

O turismo rural pode ser medido a partir de algumas características básicas: quanto à escala, quanto à localização; quanto às atividades agropecuárias; qualidade da paisagem podendo variar entre conservação dos recursos naturais conservação de características e utilização dos materiais construtivos típicos da região e cuidados com as instalações e lidas agropecuárias; também quanto aos aspectos culturais; quanto à diversificação dos serviços oferecidos; quanto à distribuição dos benefícios; quanto ao empoderamento das comunidades; quanto à sustentabilidade (BRASIL, 2008).

Observa-se que diferentes formas são usadas para classificar 0 turismo no espaço rural, como por exemplo, em relação à sua quantidade $e$ intensidade não somente quanto ao espaço onde ocorre (ALMEIDA, 2012). O fato é que o turismo rural vem sendo descoberto e cada dia mais procurado, principalmente porque busca disseminar a essência que a vida no campo proporciona para aquelas pessoas que têm uma vida urbana agitada, com tendência ao estresse que o meio rural sabe como lidar.

Com a crescente demanda, existe um número considerável de propriedades rurais que vêm agregando estratégias para promover essa atividade. Contudo, nem sempre é mantido um controle e ordens seguras para que os princípios dessa atividade não sejam perdidos e que o seguimento continue sendo uma opção de lazer para aqueles que buscam no turismo rural uma opção agradável e continue sendo oportunidade positiva de renda para os empreendedores rurais (BRASIL, 2010).

Desse modo, ressalta-se que o turismo é uma atividade que também pode desenvolver consequências negativas. Não obstante, a atenção deve ser levada em consideração nas questões ambientais ligadas à degradação ambiental, paisagística e à descaracterização do meio que a prática do turismo rural pode acarretar pelo elevado número de visitantes e veículos nas estruturas rurais (BRASIL, 2008).

Logo, o que fortalece o turismo rural em propriedades está associado à valorização pelos serviços gerados nas propriedades agrícolas e empreendimentos rurais, que envolve uma dinâmica social e econômica dos territórios rurais (BRASIL, 2008). Associando turismo e desenvolvimento, 
leva-se em consideração o pressuposto de que as atividades turísticas têm capacidade e potencial para a geração de emprego e renda e a minimização das desigualdades sociais (ARAÚJO; LOPES; TINÔCO, 2012).

Quando se fala em desenvolvimento, é importante levar em consideração as práticas sustentáveis que ligam as atividades no meio ambiente e os recursos naturais. No caso do turismo rural, "o futuro e a sustentabilidade dessa atividade dependem da qualidade do produto oferecido, pela promoção dos valores locais e da estabilidade da autenticidade cultural e da proteção ambiental" (RUSCHMANN, 2000, p. 73).

O desenvolvimento possui uma importância significativa, pois pode ser entendido, também, como uma estratégia para promover o conhecimento público em relação a determinados locais, promovendo assim 0 desenvolvimento local, além de satisfazer as necessidades de uma determinada região.

Ruschmann (1999) considera que os impactos podem não ser relevantes em alguns casos, mas em outros comprometem as condições de vida ou a atratividade das localidades receptoras do turismo. Para que o turismo proporcione efeitos favoráveis nas localidades implantadas, exige-se a conscientização dos turistas e um planejamento dos governos, além do apoio das empresas e das comunidades envolvidas. Esse planejamento deve estar associado à visão de sustentabilidade dos projetos e ações turísticas, fundamentais para a minimização dos impactos da atividade.

\section{Desenvolvimento Sustentável}

Falar de ser humano e natureza é um assunto cada vez mais complexo e preocupante, uma vez que a ação da humanidade tem tomado proporções cada vez mais ameaçadoras para a continuidade da vida humana e da permanência da vida na natureza. Desde que se iniciou o diálogo entre homem e natureza, foi possível o homem conhecer três fases, a interação, a segunda intervenção e por último a agressão (BOFF, 2012).

Sendo assim, com o passar do tempo, o ser himano foi adaptando suas necessidades e aos poucos foi usufruindo daquilo que a natureza podia lhe oferecer. A grande questão é o consumo crescente dos recursos naturais, e os problemas que o crescimento populacional desencadeou estão em ritmo diferenciado dos recursos da natureza que possuem um determinado tempo para se recompor.

Sabe-se a importância da natureza e ao mesmo tempo a riqueza dos recursos naturais nela encontrados, o que possibilita o aumento do desejo do consumismo em exploração desses recursos. O consumo cada vez mais acelerado da população, em nível mundial, acelera essa exploração, visto que "os padrões de produção e consumo de nossa civilização ameaçam a sustentabilidade dos ecossistemas e criam um círculo vicioso entre ecossistema natural e social' (ARAÚJO, 2008, p. 24).

Dessa forma, a crescente necessidade de consumo dos recursos, desde os tempos passados, passa pelo processo de extração de forma 
descontrolada da natureza, trazendo a consciência dos riscos significativos a curto, médio e longo prazo. Antigamente, a humanidade dependia da natureza, mas a sua formação natural se deu por meio de longas eras geológicas e biológicas e em curto espaço de tempo. Daí a cautela no que diz respeito à impossibilidade de a natureza recriar ou reestruturar essa fonte a qual se busca cada vez mais sem controle nem cautela (ARAÚJO, 2008).

As bases desse consumo desenfreado, fomentado pela lógica da racionalidade econômica, entraram em pautas de discussão em diversos países, em função de seu esgotamento e da impossibilidade de assegurar a gerações futuras condições de sobrevivência, convencionou o termo desenvolvimento sustentável. No Relatório Nosso Futuro Comum Desenvolvimento Sustentável é conceituado como sendo aquele que atende as necessidades do presente sem comprometer as possibilidades de as gerações futuras atenderem as próprias necessidades.

Desse modo, discutir sobre desenvolvimento é, antes de tudo, conciliar crescimento e desenvolvimento, sendo que "o tipo de desenvolvimento desejável propõe uma conciliação entre desenvolvimento e o crescimento econômico, sendo, simultaneamente, sensível à dimensão social, ambientalmente prudente e economicamente viável" (SILVA; CÂNDIDO, 2010, p. 57).

Nesse sentido Fonseca (2011, p. 430) afirma que:

\begin{abstract}
Historicamente, o conceito de "desenvolvimento sustentável" representa um avanço sobre a ideia de ecodesenvolvimento (emanado da Conferência de Estocolmo em 1972) com esse novo paradigma exigindo a construção de uma nova relação homem-natureza e cujas interpretações, muitas vezes conflitantes, vêm atrasando a implantação do novo modelo.
\end{abstract}

O desenvolvimento é dito sustentável quando parte da necessidade humana em satisfazer novas necessidades, desde que não ultrapasse os limites com o meio ambiente. Pode ser considerado desenvolvimento sustentável a utilização dos recursos naturais, pelo uso consciente das atividades que serão desenvolvidas para se obter determinado resultado. Esse conceito enfatiza a preocupação com o meio ambiente e com a melhoria da população em condições socioeconômicas. E por se tratar de um processo evolutivo, visa ao crescimento econômico, melhoria na qualidade do ambiente e da sociedade, pensando sempre nas gerações atuais e futuras (FURLANETTO; CÂNDIDO; MARTINS, 2010).

É possível promover o desenvolvimento sustentável por meio do conhecimento sobre a área, região e situação local de onde se deseja produzir. Isso evita a superexploração de locais inadequados para o desenvolvimento de atividades, o que pode ocorrer de acordo com a integração da comunidade com o meio ambiente.

Portanto, o desenvolvimento sustentável está relacionado à integração dos fatores sociais, econômicos, ambientais e institucionais, que 
permeiam a sociedade, não comprometendo as gerações futuras, visando à conservação do meio ambiente (SOUZA; ANDRADE; CÂNDIDO, 2010).

Falando em desenvolvimento local e sustentável, é possível concordar com os autores Cândido, Vasconcelos e Souza (2010, p.93), quando os mesmos afirmam:

O desenvolvimento local sustentável pode ser entendido como uma via estratégica que tem como objetivo viabilizar o tão ambicionado crescimento econômico atrelado ao desenvolvimento, buscando melhorias efetivas na qualidade de vida da população, através da criação e inclusão de mercados locais em contextos mais amplos com inclusão das esferas sociais e política.

No setor turístico, houve o aumento da preocupação com a sustentabilidade, e as pesquisas com vistas a garantir o equilíbrio e igualdade de recursos disponíveis para as gerações futuras (SCÓTOLO; NETTO, 2015). Atingir o desenvolvimento sustentável por meio das atividades turísticas pode ocorrer por intermédio de incentivos às ações que são desenvolvidas também por organizações, instituições (ALMEIDA; LACERDA, 2015).

As boas práticas de conscientização ambiental por parte dos visitantes e turistas precisam ser incentivadas pelos gestores, proprietários e funcionários como um todo das propriedades rurais, levando em consideração que o ambiente deve permanecer dentro das condições adequadas para a conservação e preservação do patrimônio natural e cultural, destacando-se entre essas práticas a coleta seletiva do lixo e sua compostagem, tratamento de efluentes e resíduos, reflorestamento, utilização de fontes alternativas de energia, conservação e gestão do uso da água (BRASIL, 2010).

No caso das propriedades rurais, a motivação para promover o seu "produto" de forma sustentável é obtida por meio de atividades com práticas e exercícios do campo, tais como passeios a cavalo, ciclístico, trilhas, cultivo de hortas, cuidado com animais de criação, gastronomia, locais de lazer como lagos, piscinas naturais entre muitas outras atividades.

O grande segredo do turismo rural está em conseguir mostrar ao turista o que ele quer ver. Entre outros fatores, oferecer uma gastronomia típica; ter uma ou mais atividades produtivas que caracterizem a propriedade; beleza natural; opções de atividades para os hóspedes acompanharem a rotina do lugar; contato com a cultura e a tradição local e acesso fácil, além da possibilidade de compra de artesanato e embutidos (CURY, 2012).

As atividades ecológicas somam-se à ideia de desenvolvimento sustentável e podem servir de auxílio no convite e transmissão de novos conhecimentos a respeito de atividades rurais. Com a utilização de um 
conjunto de indicadores, com seus respectivos critérios, possibilita a compreensão das dimensões da sustentabilidade em relação à atividade turística de um determinado destino (FALCÃO; GÓMEZ, 2012).

\section{Procedimentos metodológicos}

O Estado de Roraima está situado na Região Norte do país O último senso realizado em 2010, pelo Instituto Brasileiro de Geografia e Estatística (IBGE), demonstra que o estado possui uma área territorial de $5.687,037 \mathrm{~km}^{2}$. Situado numa região periférica da Amazônia Legal, predomina em Roraima a floresta amazônica e uma enorme faixa de savana. Com uma população estimada de 284.313 de pessoas, tem por limites a Venezuela ao norte e noroeste, Guiana ao leste, Pará ao sudeste e Amazonas ao sul e oeste (IBGE, 2010).

O mapa encontrado na Figura 1 mostra a distribuição dos 15 (quinze) municípios encontrados no Estado de Roraima e evidencia os cinco municípios que possuem as propriedades que praticam o turismo rural no estado, segundo documentos disponibilizados pela Secretaria Estadual de Planejamento e Desenvolvimento - SEPLAN e SEBRAE-RR.

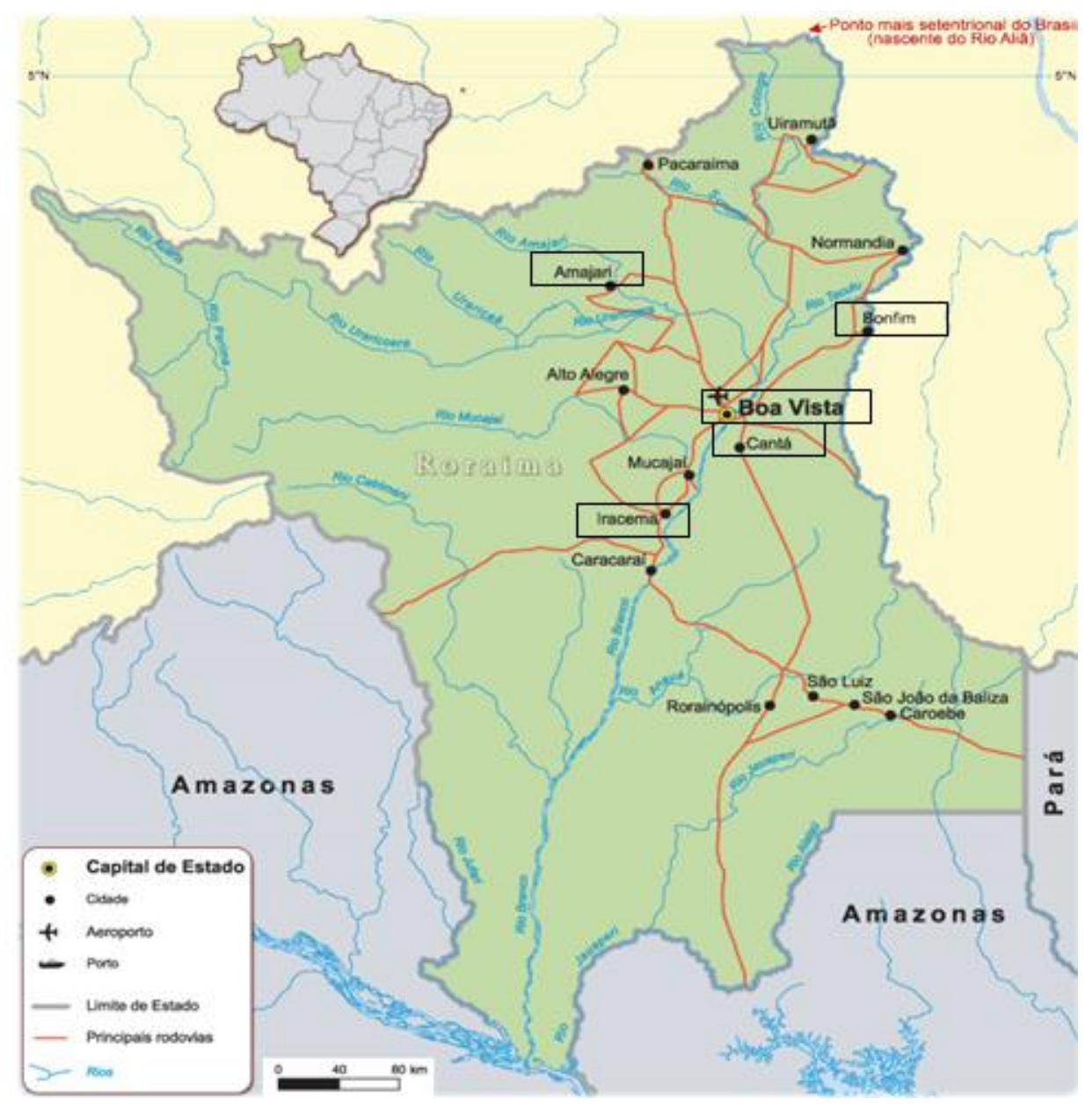

Figura 1: Mapa do Estado de Roraima. Fonte: adaptado Guia Geográfico (2016).

Figure 1: Map of the State of Roraima. Source: Adapted Geographic Guide (2016). 


\section{Seleção da pesquisa}

Quanto ao método, que consiste na escolha de procedimentos sistemáticos para a descrição das propriedades que praticam o turismo rural, utilizar-se-á a pesquisa qualitativa. Na pesquisa qualitativa, Malhotra (2006) afirma ser o tipo que se baseia em pequenas amostras para a compreensão do problema que está sendo estudado.

A estratégia de definição desta pesquisa caracteriza-se como estudo de caso, sendo aplicada em múltiplos casos. Esse tipo de estudo é definido como um "objeto de pesquisa restrito, com o objetivo de aprofundar-lhe os aspectos característicos" (SANTOS, 2006, p.27). O estudo de múltiplos casos segundo Yin (2005), permite o estudo de mais de um caso, possibilitando a comparação entre os que foram estudados para obtenção de resultados.

\section{Instrumentos de coleta de dados}

Quanto aos meios, a pesquisa é bibliográfica, já que "[...] é feita a partir do levantamento de referências teóricas já analisadas e publicadas por meios escritos e eletrônicos, como livros, artigos científicos, páginas de web sites" (FONSECA, 2002, p. 32). "[...] a pesquisa bibliográfica implica em um conjunto ordenado de procedimentos de busca por soluções, atento ao objeto de estudo, e que, por isso, não pode ser aleatório" (LIMA; MIOTO, 2007, p. 38). Quanto aos fins, é de natureza descritiva, sendo realizada com o objetivo de descrever as características de um fenômeno (GERHARDT; SILVEIRA 2009).

Foram realizadas entrevistas com os responsáveis das propriedades que praticam o turismo rural no Estado de Roraima, do projeto, "Vivendo Roraima pelos Cavalos Lavradeiros", além da observação direta.

\section{População e amostra}

Para Gerhardt e Silveira (2009), uma amostra é "parcela significativa da população ou do universo pesquisado, geralmente aceita como representativa".

Ao realizar um levantamento prévio de informações junto ao Departamento de Turismo da SEPLAN, (Secretaria Estadual de Planejamento e Desenvolvimento), para o conhecimento das empresas enquadradas no "roteiro da Amazônia rural" que praticam o turismo rural local, foram identificadas 10 (dez) propriedades que já desenvolvem a atividade no estado.

Os participantes da pesquisa serão os empreendedores/proprietários de 6 (seis) propriedades. Na apresentação dos resultados, as seis propriedades estudadas estão nomeadas em Fazenda A, Fazenda B, Fazenda C, Fazenda D, Fazenda E e Fazenda F. 


\section{Resultados e discussão}

\section{Caracterização do projeto}

Em Roraima, foi criado o primeiro roteiro de turismo rural, que está contemplado no Plano Plurianual do Governo do Estado, denominado "Vivendo Roraima pelos Cavalos Lavradeiros", resultado de uma parceria entre o Departamento de Turismo da SEPLAN (Secretaria Estadual de Planejamento e Desenvolvimento) juntamente a empresa Brasil Turismo (FOLHAWEB, 2015).

De acordo com o Ministério do Turismo (2010, p.9):

É necessário o esforço coletivo para diversificar e interiorizar o turismo no Brasil, com o objetivo de promover o aumento do consumo dos produtos turísticos no mercado nacional e inseri-los no mercado internacional, contribuindo, efetivamente, para melhorar as condições de vida no País.

\section{Fazenda $A$}

A primeira fazenda estudada, aqui denominada "fazenda A" está localizada no município de Bonfim no estado de Roraima. Possui atividades rurais iniciadas no ano de 1990 e tem cerca de 2.176 hectares de área de extensão.

Em entrevista direta com o proprietário, ele afirmou que o modelo de turismo praticado em sua propriedade, é diferente do turismo praticado no Estado por sua propriedade ser totalmente voltada à produção agrícola e criação de animais de corte como meios mantenedores da propriedade, além da busca incansável pelo equilíbrio da natureza.

O meio de renda, que sustenta a propriedade é a criação de animais e também a agricultura irrigada por meios de sistemas de irrigação e fertirigação. Atualmente a propriedade possui uma agricultura centrada na produção de melancia, maracujá, banana e macaxeira. Essa produção é vendida para Manaus e algumas frutarias da capital Boa Vista.

Além da agricultura, também é realizada a criação de gado para corte e alguns outros animais como galinhas, marrecos, capivaras, cavalos, porcos, onde alguns destes animais são criados e domesticados para consumo dos moradores da propriedade.

. Durante a entrevista foi informado que recentemente, ainda no ano de 2016 a fazenda recebeu em seu extenso lago um peixe boi, que foi levado pelos funcionários do IBAMA do estado de Roraima.

Há cerca de 10 anos os proprietários estão na tentativa de inserir o turismo rural na propriedade, devido a sua riqueza natural, o contato direto com a natureza, a presença de um imenso lago artificial, criação de animais, prática da agricultura e espaço propício ao camping.

Até pouco tempo o lago presente na propriedade era bastante frequentado por alguns moradores do município de Bonfim e alguns visitantes da Guiana Inglesa, sem ser cobrado taxa de utilização do espaço. Mas, por se 
tratar de um ambiente totalmente natural e que necessita de cuidados na conservação do espaço, os proprietários passaram a perceber que o local, poderia ser explorado e aprimorado à prática do turismo rural, visto que sempre havia uma constante presença de visitantes no local.

Assim sendo, os proprietários estabeleceram um valor mínimo para a utilização e visitação da sua propriedade, com o intuito de complementação de renda e com o intuito de aos poucos promoverem o aprimoramento do turismo na fazenda. Sendo que para uma enorme surpresa, logo na primeira tentativa de cobrar a pequena taxa de entrada o número de visitantes caiu drasticamente, chegando ao ponto de nos dias atuais a propriedade não recebe mais turistas nem visitantes em sua fazenda.

Como uma alternativa de voltar a receber o público na fazenda, os proprietários se dispuseram a participar do projeto do SEBRAE do estado e assim participaram de vários cursos de orientação e capacitação, com 0 principal objetivo de enquadrar sua propriedade e adaptá-la ao turismo rural em busca da complementação de renda e a busca de novos conhecimentos que somariam para o sucesso do empreendimento. Após dois anos participando do projeto, a propriedade chegou a receber alguns grupos organizados pelo SEBRAE, que ao visitarem Lethem, na Guiana Inglesa passaram pela fazenda e puderam desfrutar de momento de lazer, tranquilidade e degustar uma refeição típica de uma fazenda, além da visita às produções agrícolas e as diversas atividades de lazer encontradas no local. Tudo isso foi possível graças à parceria da fazenda junto ao SEBRAE que promoveu o pacote de viagem com os turistas.

De acordo com o IDESTUR, Instituto de Desenvolvimento do Turismo Rural, o crescimento acelerado pela modalidade do turismo rural acaba gerado uma confusão pelas suas múltiplas concepções, manifestações e definições. Isso em grande parte é causado pela falta de algumas ações que organizam e incentivam o que oficializa o real sentido do Turismo Rural, "como um segmento turístico, fazendo com que a vasta diversidade cultural e geográfica do País, ao invés de caracterizar e identificar cada lugar, tenda à descaracterização" (IDESTUR, 1998, p. 5).

Após a conclusão do projeto, proposto e oferecido pelo SEBRAE, os proprietários não mais conseguiram receber visitantes e a prática do turismo encontra-se parada, pois, sem um convênio ou parcerias com empresas de turismo a divulgação da propriedade não acontece e fica limitada a prática desta atividade, concluiu o proprietário ao final da entrevista.

\section{Fazenda B}

A segunda fazenda estudada fica localizada no município do Cantá. No projeto do Departamento de Turismo da SEPLAN (Secretaria Estadual de Planejamento e Desenvolvimento) do Estado de Roraima em parceria com o SEBRAE é possível encontrar na propriedade área de lazer com oferta de gastronomia típica, trilhas na mata e ervas medicinais. O local é conhecido e frequentado por possuir um extenso balneário que permite ao visitante desfrutar do contato direto com a natureza e refrescar-se no lago, 
principalmente nos períodos quentes. O local funciona aos finais de semana e também por agendamento prévio.

Atualmente, de acordo com as informações obtidas por pesquisas indiretas com as outras fazendas pesquisadas, foi informado que nesta propriedade os proprietários trabalhavam com trilhas ecológicas e a demonstração do proprietário e exposição de seus conhecimentos com algumas plantas medicinais, porém por falta de condições financeira e desprovida de apoio das entidades públicas locais não foi possível dar continuidade a essas atividades e hoje a propriedade só disponibiliza o extenso lago encontrado no local, oferecendo apenas este balneário como atrativo de turistas e visitantes locais. Desta forma essa prática não é considerada como turismo rural.

Visto que quanto aos objetivos do turismo rural:

Os seus objetivos deverão contemplar a otimização e a contribuição do setor do turismo e hospitalidade para melhoria da qualidade de vida das pessoas e do meio ambiente, integrando-se de forma harmônica com as demais atividades sociais e econômicas (DENCKER, 2004, p. 1).

Em diversas tentativas de contato com os proprietários, não foi possível conhecer a propriedade nem aplicar a entrevista devido o não funcionamento do local nos últimos meses justificado pelo período chuvoso na região.

\section{Fazenda $C$}

A fazenda C fica localizada no município de Boa Vista. No projeto do Departamento de Turismo da SEPLAN (Secretaria Estadual de Planejamento e Desenvolvimento) do Estado de Roraima, junto ao SEBRAE, é possível conhecer a propriedade através do agendamento de visitas, o plantio sustentável de açaí além da degustação de açaí na tigela.

Para conhecer a propriedade os interessados devem agendar a visita diretamente com o proprietário por telefone. Para compras de açaí a propriedade disponibiliza o produto a cada quinze dias no próprio sítio, pois o proprietário possui outras atividades em outro município e não se dedica exclusivamente a plantação e produção de açaí. Em relação à vivência e a prática do turismo rural, estas atividades não podem ser observadas por se tratar de uma propriedade voltada apenas para à produção de açaí, além de ser uma produção pequena, pois só atende a compradores locais. E por isso não apresenta atividades voltadas ao campo, que é uma característica básica para a prática do turismo rural. O turismo rural se caracteriza como "[...] a atividade turística correlacionada a atividades agrárias, passadas e presentes, que conferem à paisagem sua fisionomia nitidamente rural' (RODRIGUES, 2001, p. 103). 


\section{Fazenda $D$}

Também localizada no município do Cantá, a fazenda $D$, projeto do Departamento de Turismo da SEPLAN (Secretaria Estadual de Planejamento e Desenvolvimento) do Estado de Roraima, em parceria com o SEBRAE era possível encontrar na propriedade alimentação, hospedagem em chalés, pescaria e diversas atividades de lazer. Com funcionamento todos os dias da semana.

Entre diversas visitas à propriedade o local se encontrava fechado ao público e não havia responsáveis nem os proprietários no rancho. Entre tentativas de contato, por telefone, com os proprietários conseguiu-se uma única resposta, por um antigo funcionário e o mesmo informou que o rancho já se encontra fechado há vários meses e quando questionado o motivo ele não soube explicar, assim como não foi informado o contato dos proprietários para um melhor esclarecimento da real situação da propriedade.

\section{Fazenda $E$}

A fazenda $E$ se localizava em Boa Vista na capital do Estado de Roraima. Com base no projeto do Departamento de Turismo da SEPLAN (Secretaria Estadual de Planejamento e Desenvolvimento) do Estado de Roraima, junto ao SEBRAE, era possível encontrar na propriedade atividades culturais e rurais. Ecomuseu da Cultura indígena, eventos culturais e gastronomia regional, funcionando por meio de agendamento.

Mesmo participando de todo o projeto atualmente a propriedade não funciona aberta ao público para a recepção de turistas. Entre diversas tentativas de contato com o proprietário a única informação obtida foi de que a propriedade não se encontra aberta ao público.

\section{Fazenda $F$}

A fazenda $F$ está localizada no município do Cantá no estado de Roraima e desenvolve atividades rurais desde 1998. O turismo é uma atividade nova, que vem sendo praticada desde 2013.

Os proprietários participaram de todo o projeto promovido pelo Departamento de Turismo da SEPLAN (Secretaria Estadual de Planejamento e Desenvolvimento) do Estado de Roraima, junto ao SEBRAE. Com o objetivo de inserir a propriedade na prática do turismo rural e com intuito de conhecer o potencial da propriedade e assim utilizar como ferramenta de captação de novos visitantes.

Os proprietários residem na fazenda e praticam a criação de animais, plantio de hortaliças para consumo da propriedade, além de ter como objetivo a promoção da cultura e educação. Na fazenda é possível encontrar um amplo espaço verde e arborizado, com a residência dos proprietários, um espaço para camping, um galpão construído para o provimento de reuniões e palestras e espaços para criação de animais pequenos como galinhas e marrecos e para plantio. 
Devido ao período chuvoso, atualmente, não há animais na propriedade, mas, em breve a criação será reiniciada mas apenas para o consumo da família.

Durante a entrevista a proprietária afirmou que as atividades rurais, tais como criação de animais, produção agrícola, eram desenvolvidas no local, porém, um dos fatores que dificulta a continuidade do negócio é a barreira para a comercialização desses produtos nas feiras e comércio local.

Um impasse que ocorre na região, onde a propriedade está localizada, é o fato que no período entre Março a Julho com o início das chuvas, que anunciam o inverno, o acesso à propriedade fica ruim e isso impede a entrada de carros pequenos, o que dificulta a prática do turismo no local.

Não é cobrada taxa de entrada no local, os proprietários trabalham por meio de agendamento e promovem o desenvolvimento e busca continua da qualidade de vida. Ao agendar a visita no local é fechado um pacote que inclui a alimentação do grupo, dependendo da quantidade de pessoas que pretendem visitar a propriedade. Atualmente há um grupo de religiosos que mensalmente frequentam o local.

Portanto esta propriedade também não possui característica de turismo rural pela deficiência de uma proposta única para padronizar as propriedades que possuem interesse em se adequar a esta atividade.

Os impasses encontrados para os incentivos às pequenas propriedades já eram ressaltados por Elesbão (2000, p 246), quando o autor já afirmava:

A restrição de crédito para financiar a agricultura, a queda dos subsídios, os juros elevados, a elevação dos preços de insumos levaram a produção primária e, consequentemente, o meio rural a uma crise social e econômica sem precedentes nas últimas décadas.

Ao mesmo tempo em que é vista a oportunidade de se inserir a atividade de turismo nas pequenas propriedades também ocorrem os impasses para o seu desenvolvimento.

Durante a pesquisa foi frisado pelo entrevistado que sem o apoio técnico do SEBRAE, no incentivo e instrução aos pequenos negócios e o interesse dos proprietários no aprendizado e promoção de sua propriedade, é impossível inserir o turismo de maneira correta e frequente e torna-la uma alternativa rendável à propriedade, pela carência dos meios de divulgação como as agências de turismo. Ou seja, essa parceria é fundamental para o desenvolvimento do turismo rural no Estado para os pequenos empresários locais. 


\section{Considerações finais}

Roraima fica localizado no extremo Norte do Brasil e se posiciona entre dois países que são Venezuela e Guiana Inglesa, assim como também fica bem próxima a Manaus, metrópole regional. A promoção da modalidade do turismo rural, que possui potencial de desenvolvimento local pode garantir 0 reconhecimento do estado.

O turismo rural pode ser considerado uma oportunidade para as pequenas propriedades que desejam complementar suas rendas. Além de proporcionar, ao estado, grandes chances de reconhecimento nacional e mundial por permitir a disseminação das riquezas culturais e naturais presentes em Roraima.

Um dos fatores que impede esse desenvolvimento é o precário incentivo e investimento voltado a essa atividade, incluindo também a falta de um modelo base para a implantação do turismo rural, que poderia ser desenvolvida, com base em informações e pré-requisitos básicos para as propriedades que desejam se adequar a atividade por parte do próprio estado, onde, "(...) o poder público pode desestimular a iniciativa privada ao criar instrumentos legais sem captar a fundo a essência da atividade turística" (ALEXANDRE, 2003, p. 1).

Dentre as propriedades inclusas no projeto é possível concluir que 06 delas não possuem a prática correta do turismo rural. Pois, não foram apresentadas, nessas propriedades, características significativas para 0 desenvolvimento do turismo.

Pôde ser observado durante as entrevistas, que algumas dessas seis propriedades analisadas ainda "tentam" funcionar com atividades turísticas com a oferta de banhos, encontros religiosos, atividades de camping e passeios. Outras já se encontram fechadas ao público. Com isso não podem ser consideradas detentoras do título de propriedades com a presença do turismo rural.

A inexistência de um projeto consolidado para promoção do turismo rural em Roraima dificulta ainda mais essas propriedades se adequarem aos padrões desta modalidade de turismo. Causando pouco interesse dos órgãos governamentais e da iniciativa privada. Se comparado a outros Estados percebe-se a deficiência desta atividade no extremo Norte do País. Inibindo assim o crescimento do Estado em relação ao turismo e limitando o desenvolvimento da região. É importante que os órgãos competentes passem a enxergar que a atividade turística tem papel de maior relevância no desenvolvimento turístico, e na importância de reconhecer não apenas que o setor gera impactos, mas principalmente passe a ver o poder de crescimento de revitalização social e cultural (OMT, 2003).

A prática do turismo rural tem valor significativo ao pequeno produtor, pois oferece oportunidade as áreas rurais. É necessário um olhar voltado ao futuro desta atividade. A qualidade do produto, a disseminação dos valores locais e culturais também levando em consideração a proteção do meio ambiente. Para que o turismo rural ganhe cada vez mais vantagens ocorra essa promoção do desenvolvimento local, são necessários planejamento, 
junto aos produtores da atividade e a disponibilidade de parcerias que vão proporcionar o crescimento nesta modalidade de turismo.

\section{Referências}

ALBACH, V.M. Panorama da Pesquisa em Turismo nos Mestrados em Geografia do Brasil: o caso do mestrado em Geografia da UFPR. Dissertação (Mestrado em Geografia) - Universidade Federal do Paraná, 2010.

ALEXANDRE, L.M.M. Política de turismo e desenvolvimento local: um binômio necessário. In: BEZERRA, D.M.F. Planejamento e gestão em turismo. São Paulo: Roca, 2003.

ALMEIDA, F.A.B. Turismo, produção do espaço, ruralidade e gestão social. In: CORRÊA, M.L.; PIMENTA, S.M.; ARNDT, J.R.L. (Org.). Turismo, sustentabilidade e Meio ambiente: contradições e convergências. Belo Horizonte: Autêntica, 2009. p. 49-71.

ALMEIDA, N.P. Políticas públicas e dinâmicas do turismo no espaço rural. In: THOMAZ, R.C.C.; MARIANI, M.A.P.; MORETTI, E.C. (Org.). O turismo rural e as territorialidades na perspectiva do campo e da cidade. Campo Grande: UFMS, 2012. p. 59-78.

ARAÚJO, G.F. Estratégias de sustentabilidade: aspectos científicos, sociais e legais - contexto legal - visão corporativa. São Paulo: Letras Jurídicas, 2008. $125 \mathrm{p}$.

ARAÚJO, R.M.; LOPES, A.O.B.; TINÔCO, D.S. Turismo como vetor de desenvolvimento local: um olhar através das ideias de Theodor Adorno e Max Horkheimer. Revista Turismo em Análise, São Paulo, v. 23, n. 1, p. 104-127, abr. 2012.

BANDUCCI JR, A.; BARRETO, M. (Org.). Turismo e identidade local: uma visão antropológica. Campinas: Papirus, 2001.

BARBOSA, F.F. O turismo como um fator de desenvolvimento local e/ ou regional. Caminhos de geografia, Minas Gerais, v. 10, n. 14, p. 107-114, fev. 2005.

BARTELÓ, C. Costas da Bahia. Viver BAHIA, Salvador, v. 5, n. 8, p. 30-31, 2000.

BETTI, P.; DENARDIN, V.F. Turismo de base comunitária em Unidades de Conservação: justiça ambiental para o desenvolvimento local. Revista Brasileira de Ecoturismo, São Paulo, v. 6, n. 4, p. 176-190, nov. 2013.

BOFF, L. Sustentabilidade: o que é - o que não é. Petrópolis: Vozes, 2012. 200 p.

BRASIL. Ministério do Turismo. Turismo rural: orientações básicas. Brasília: Ministério do Turismo, 2008. 52 p. Disponível em: <http://portal.mda.gov.br/o/2955271>. Acesso em: 07 Out. 2015. 
BRASIL. Ministério do Turismo. Turismo Rural. 2 ed. Brasília: Ministério do Turismo, $2010.272 \quad$ p. $\quad$ Disponível em: $<$ http://www.turismo.gov.br/sites/default/turismo/o ministerio/publicacoes/dow nloads publicacoes/Turismo Rural Versxo Final IMPRESSxO .pdf>.

Acesso em: 29 out. 2015.

CÂNDIDO, G.A.; VASCONCELOS, A.C.F.; SOUZA, E.G. Índice de desenvolvimento sustentável para municípios: uma proposta de metodologia com a participação de atores sociais e institucionais. In: CÂNDIDO, G.A. (Org.). Desenvolvimento Sustentável e Sistemas de Indicadores de Sustentabilidade: Formas de aplicações em contextos geográficos diversos e contingenciais específicas. Campina Grande: UFCG, 2010. p. 87-117.

CURY, M.J.F. As territorialidades ambientais no meio rural Brasileiro e no oeste do Estado do Paraná. In: THOMAZ, R.C.C.; MARIANI, M.A.P.; MORETTI, E.C. (Org.). 0 turismo rural e as territorialidades na perspectiva do campo e da cidade. Campo Grande: UFMS, 2012. p. 141-154.

DANTAS, N.G.S.; MELO, R.S. O método de análise SWOT como ferramenta para promover o diagnóstico turístico de um local: o caso do município de Itabaiana / PB. Caderno virtual de turismo, Rio de Janeiro, v. 8, n. 1, p. 118130, jan. 2008.

DENCKER, A. Planejamento e gestão de hospitalidade e turismo: formulação de uma proposta. In: DENCKER, A.M. (Coord.). Planejamento e gestão em turismo e hospitalidade. São Paulo: Thomson Pioneira, 2004.

ELESBÃO, I. O turismo como atividade não agrícola em São Martinho-SC. In: ALMEIDA, J.A.; RIEDL, M. (Orgs.). Turismo Rural: ecologia, lazer e desenvolvimento. Bauru-SP: EDUSC, 2000. p. 245-263.

FALCÃO, M.C.; GÓMEZ, C.R.P. Análise da sustentabilidade de destinos turísticos: uma proposta teórica de adequação do modelo de ciclo de vida de áreas turísticas às dimensões da sustentabilidade. Revista Turismo Visão e Ação, Itajaí, v. 14, n. 3, p. 304-321, set./dez. 2012.

FOLHAWEB. Boa Vista: Folha de Boa Vista, 2015. Disponível em: $<$ http://www.folhabv.com.br/noticia/Primeiro-roteiro-de-turismo-rural-seralancado-em-Roraima/10255>. Acesso 29 set. 2015.

FONS, M.V.S.; FIERRO, J.A.M.; PATIÑO, M.G. Rural tourism: A sustainable alternative. Applied Energy, [s. I.], v. 88, n. 2, p. 551-557, fev. 2011.

FONSECA, J.J.S. Metodologia da pesquisa científica. Fortaleza: UEC, 2002. $212 \mathrm{p}$.

FONSECA, O.J.M. Pensando a Amazônia. Manaus: Valer, 2011. 496 p.

FURLANETTO, E.L.; CÂNDIDO, G.A.; MARTINS, M.F. Sustentabilidade em arranjos produtivos locais: uma proposta metodológica de análise. In: CÂNDIDO, G.A. (Org.). Desenvolvimento Sustentável e Sistemas de Indicadores de Sustentabilidade: Formas de aplicações em contextos geográficos diversos e contingenciais específicas. Campina Grande: UFCG, 2010. p. 118-151. 
GERHARDT, T. E. SILVEIRA, D. T. Métodos de pesquisa. Porto Alegre: UFRGS, 2009.

GUIA GEOGRÁFICO. Disponível em: <http://www.guiageo.com/roraima.htm>. Acesso em 02 mar. 2016.

Instituto Brasileiro de Geografia e Estatítica (IBGE) Senso 2010.

IDESTUR. Instituto de Desenvolvimento do Turismo Rural. Ministério do turismo. Diretrizes para o desenvolvimento do turismo rural no Brasil. 1998. Disponível em: <http://www.idestur.org.br/download/E Diretrizes TR.pdf>. Acesso em 26 Ago. 2016.

LIMA, T.C.S.; MIOTO, R.C.T. Procedimentos metodológicos na construção do conhecimento científico: a pesquisa bibliográfica. Revista Katál, Florianópolis, v. 10, ed. esp., p. 37-45, abr. 2007.

MALHOTRA, N.K. Pesquisa de marketing: uma orientação aplicada. 4. ed. Porto Alegre: Bookman, 2006. 720 p.

OMT. Turismo internacional: uma perspectiva global. 2. ed. São Paulo: Bookman, 2003.

RODRIGUES, A.A. Turismo e Espaço: Rumo a um conhecimento transdisciplinar. São Paulo: Hucitec, 1997. 147 p.

RODRIGUES, A.B. Turismo rural no Brasil: ensaio de uma tipologia. In: RODRIGUES, A.B. (Org). Turismo rural. São Paulo: Contexto, 2001.

RUSCHMANN, D.V.M. Turismo e Planejamento Sustentável: a proteção do meio ambiente. 4. ed. Campinas: Papirus, 1999. 199 p.

SANTOS, A.R. Metodologia Científica: a construção do conhecimento. 6. ed. Rio de Janeiro: DP\&A, 2006. 150 p.

SANTOS, J.G. Sistema de Indicadores de Sustentabilidade para o Turismo: aplicação de uma abordagem participativa em Porto de Galinhas, PE. 2013. 219 p. Dissertação (Mestrado em Administração). - Universidade Federal de Pernambuco, 2013.

SCÓTOLO, D.; NETTO, P. A. Contribuições do turismo para o desenvolvimento local. Revista de cultura e turismo, Salvador, v. 9, n. 1, p. 36-59, fev, 2015.

SILVA, M.G.; CÂNDIDO, G. A. Método de construção do índice de desenvolvimento local sustentável: uma proposta metodológica e aplicada. In: CÂNDIDO, G.A. (Org.). Desenvolvimento Sustentável e Sistemas de Indicadores de Sustentabilidade: Formas de aplicações em contextos geográficos diversos e contingenciais específicas. Campina Grande: UFCG, 2010. p. 54-86.

SOUZA, E.G.; ANDRADE, E.O.; CÂNDIDO, G.A. A aplicação das dimensões do desenvolvimento sustentável: um estudo exploratório nos municípios produtores de leite bovino no Estado da Paraíba. In: CÂNDIDO, G.A. (Org.). Desenvolvimento Sustentável e Sistemas de Indicadores de Sustentabilidade: Formas de aplicações em contextos geográficos diversos e contingenciais específicas. Campina Grande: UFCG, 2010. p. 152-175. 
Yin, R. Estudo de caso: planejamento e métodos. 2. ed. Porto Alegre: Bookman, 2005. $187 \mathrm{p}$.

Suelen Santos Bezerra: Universidade Federal de Roraima, Boa Vista, RR, Brasil.

E-mail: suelen.sts@gmail.com

Link para o currículo Lattes: http://lattes.cnpq.br/3671418215431503

Georgia Patrícia da Silva Ferko: Universidade Federal de Roraima, Boa Vista, RR, Brasil.

E-mail: geoufpe@yahoo.com.br

Link para o currículo Lattes: http://lattes.cnpq.br/8762583706265854

Data de submissão: 30 de agosto de 2016

Data de recebimento de correções: 23 de março de 2018

Data do aceite: 23 de março de 2018

Avaliado anonimamente 